\title{
THE CHEMICAL PROBLEMS OF TO-DAY.
}

An address delivered at Heidelberg at the first general session of the sixty-second meeting of The Association of German Naturalists and Physicians, Sept. 18, 1889,*

BY VIC'TOR MEYER,

TRANSLATED BY L. H. FRIEDBURG.

When, a short time ago, I was called upon to speak before you, I gladly and zealously approached the work, which such an occasion seemed to call forth. It seemed to me that it would be an effort worthy of this assemblage of scientific men to recall the permanent additions that chemistry has made in our day to the treasure of human knowledge and to enumerate the problems which seem to lie nearest us in the future.

A science which, as such, is hardly older than the great European revolution, the centennial of which wo wituessed a few months ago, and which in this short time has caused changes in our spiritual and material life hardly less than those of the political revolution, such a science, I have thought, may, without temerity boast of its achievements.

And yet the chemist approaches such a task, with a certain hesitation, from which the astronomer, the physicist and the mathematician are free. Has it not been in our own day that the most prominent orator amongst German naturalists, one who astonishes us by the comprehensiveness of his knowledge, has adopted as his own $\mathrm{Kant}$ 's judgment on chemistry, namely that "chemistry is a science, but not a science in the highest sense of the word, that is, a knowledge of nature reduced to mathematical mechanics." And this dictum is accepted, not

*Deutsche Rundschau. Nov,, 1889. 
as a blemish upon our science, but with the fullest and most perfect recognition of the immense achievements which modern chemistry has registered as its own.

But all of the marvelous successes of the atomic theory and of the doctrine of structure; the synthesis of the most complicated organic compounds; the blessings of an enlarged pharmacopia, the potent revolution in technological processes, the new and systematic methods of production which have been characterized by an eminent technologist as "the gaining of gold from rubbish"-all this seems trifling to the mind that looks down from its standpoint of mathematical mechanies when compared with the work of. a promised $\mathrm{New}$ ton of chemistry, who some day will represent chemical reactions in the thought and in the language of mathematical physios.

And if he who looks from at height is justified in the expression that to-day chemistry, in the recognition of ultimate causes, stands yet below astronomy of the time of $K \in p l e r$ and $C o p e r-$ $\mathrm{n}$ i cus, must not the chemist lose courage if he attempts, before an illustrious assemblage, to raise it song of praise to his science, to glorify what she has done and what in the future she seems chosen to do? If in spite of this the attempt be made, it must be with that resiguation which rests upon the belief that "we should consider everything but to aim only at that which is possible."

Thongh we share, with full conviction, the expectations of a Newtonian period in chemistry, we hardly renture to hope that that period is near, and even the most enlightened representatives of the newer physical chemistry seem but precursors of that distant era.

Perhaps the chemist, immersed in the daily work of his science, fails to take the comprehensive view of one who from a distant height looks down upon the same. But those who are surrounded by the whirl of hourly renewed work recognize, all the more clearly, the immense amount that remains still to be achieved before those distant aims can be realized. This epoch, so rich in path finders in the department of physics, has rarely directed the highest order of research in to the territory of our science and especially have the more complicated chemical phenomena been aroided. 
If in a period that has witnessed the discoveries of $\mathrm{Helm}$ holtz, Robert Mayer, Joule, Clausius, and van't $\mathrm{H}$ of $\mathrm{f}$, the revolutionizing progress of knowledge has been limited to Physics, and if only modest applications of what was gained have been made in related studies, then the epoch seems not yet to be at hand in which chemical processes can be thought of as we think of the movements which we feel as sound, light or heat.

A humiliating statement! But, strange to say, the chemist of to-day has hardly time to complain of this resignation imposed upon him, and this for reasons easily understood:

If-without question-it is the aim of all natural science to understand phenomena so fully that they may be described in a mathematical form and, as far as they are unknown, may be predicted, a science, which is so far distant from this aim as to look merely for the path that shall some day lead to it, must be considered as in its infancy. In the present stage our way of thinking and acting has this peculiarity. In every science phantasy must stand as another power alongside of knowledge and reasoning. But the influence of phantasy upon knowledge is all the greater the further this latter is distant from the mentioned ideal. And thus it happens, that in the chemistry of to-day, phantasy and intuition have a larger scope than in other sciences, and that occupation with the same, besides the pure scientific satisfaction that it yields brings an enjoyment which, in a certain sense, reminds one of the activity of an artist. He, however, who only knows chemistry as a tradition of perfectly clear facts, or who thinks to see the real soul of chemical study in measuring the plyssical phenomena which accompany chemical transformations feels no breath of this enjoyment.

The feeling is only disclosed to him who ventures into that ocean of the unknown that is spread out before us in the organic chemistry of the day; to him who is not appalled by a wilderness, populated with thousands of individuals of which every one shows a peculiar, fully unknown originality, and to him who attempts to become better acquainted with some of them, even if he is at a loss for a means of approaching them. To proceed with 
success in this direction is only granted to the genius-the method that leads onward cannot be learned, and it has only been practiced with, success by a small number of chosen ones.

Indeed, in the experimental study of organic chemistry, the "presentiment" of happenings, the actuality of which is not indicated by any law to be expressed in words, has shown surprising results : here the thought is aided by a something, which we may meanwhile term "chemical feeling," a name which will disappear as soon as the progressive approach of chemistry to the mathematical physical basis shall have disclosed its meaning and shall have tabulated it amongst the methods which lead to the recognition of the new. The effect of this pecnliar chemical method of study is not here to be dwelt upon in detail. Let it suffice to say, that withont it the most brilliant discoveries in organic chemistry would not have been made, just as little as a $\mathrm{Keknl} 6$ wonld, without it, have been unable, in contradiction of numerous data in chemical literature never before donbted, to atfirm the nonexistence of isomeric monochlorbenzol and of such bodies as were said to consist of a benzol ring and but one bivalent atom. Those significunt hypotheses by means of which the knowledge of aromatic substances has been revealed to us, could not have been made solely upon the ground of exact observation, they required at the same time a pronounced chemical instinct. There was no logical renson in declaring the existence of a phenylene oxide as an impossibility, since the ethylene oxide did exist; he who nevertheless rentured to do so and at the same time ran directly in the face of experience, was surely led by a feeling which the present status of chemistry forbids us to replace by a process of thought.

But to return from the field of organic to that of general chemistry. Before we can arrive at a mathematico-physical treatment of chemical phenomena in general, two fundamental problems must be solred : an hypothesis which allows a control by experiment (even within the same limits which to this day are imposed upon physics in regard to the law of gravitation)-must answer these questions: What is Chemical Affinity? and, What is Trulency? 
By means of laborious detail-work chemistry tries to approach the solution of these enigmas, but he who pursues chemical methods, who stands in the midst of chemical work-which aims only, as at a far distant task, at the discovery of a sure pathstill sees such obstacles to be cleared away, that he gives up the hope of living to see the new chemical era. He finds satisfaction in the consciousness of having exerted his best abilities in the elucidation of some minor and precursory principles.

If now we begin to consider-within the appointed limits-the most important achievements of chemistry, we cannot, at this place and at this hour of our meeting, be in doubt as to what is to be mentioned in the first place. The hospitable city that shelters us boasts of an advantage which is envied her by every other Alma Mater: here, chemistry for more than a human lifetime has been represented by $\mathrm{R}$ ober t $\mathrm{Bunsen}$, of glorious name, and the very days which find us here assembled, follow immediately the moment in which this hero of science has retired from his academical occupation. Who does not think, at such an hour, of the great teacher around whom ardent pupils from all parts of the globe were accustomed to congregate. But who, being called upon to-day to speak of the results of chemistry within the walls of Heidelberg, would not before all direct an eye upon that one discovery which has lifted chemistry beyond terrestrial research, which has enabled her, like astronomy, to search the universe and to dissect the starry heavens, chemically, by the subtle appliances of analysis. If "old Heidelberg" has become a pearl amongst German cities by its history, by its numerous traditions, by the incomparable beauty of its situation-if its university is the ideal of the German academical youth, we may well regard as an immortal leaf in its wreath of honor, along with these glorious titles, the union of those two great men who first met in this city in the most courageous enterprise of the penetrating mind; who have pursued with astonishing success the investigation which has made spectral analysis the most potent of scientific weapons, and has rendered their names a charm calling forth the admiration of the older minds and kindling in the minds of mere schoolboys the flame of enthusiasm in the study and exploration of 
nature. The immeasurable results of that discovery-the consequences of which extend every day orer new territories-are known in the widest circles and to mention them to-day in detail would be but carrying owls to Athens. It behooves us in this place to mention reverently the names of $B u$ u se n and $K$ i $r$ ch h o ff, to think of them with gratitude, and to hope that men, their equals, may not be entirely wanting in the next generation: The younger one of them-whose scientific fertility was only equaled by his greatness of soul and the charming modesty of his heart-has been taken away from us before old age had naturally limited him. B unsen we still rejoice to call ours, who now, allowing the tools of his work to drop from his hand, looks forth to the evening of his life in quiet, happy leisure. May he be permitted for a long time to look back upon a life filled with greatest scientific achievements; may his calm, friendly ere rest for many years upon the incomparable picture of his beloved Heidelberg.

We have mentioned spectral analysis, though it has been almost for an age the common property of science. Let us also cast a grateful retrospect upon a cheeply furrowing revolution-of which chemistry also, for several decades, has boasted as a substantial possession-a pon the development of the doctrine of structure, that solid theoretical foundation from which the proud edifice of modern organic clemistry rises. A generation has grown up around us which has received as a matter of fact this doctrine which still seems new to us older ones. But those far-seeing men, whose eyes recognized the immensely simple in the seemingly impenetrable complication of the earbon compounds, are still actifely alive amongst us, and it is their happy lot to reap in their own activity what once they sowed in juvenile work. Here the eye is directed upon the master of chemical research-A u gust Wilhelm von Hofmann: before all upon his researches upon the organic nitrogenous bases-researches which do not find their equal in organic chemistry and which, even more perfectly than $\mathrm{D} u \mathrm{mas}$ ' fundamental discovery of trichloracetic acid, allowed the fundamental conception of substitution to expand into the living consciousness of chemists, at first, curiously, by supporting the theory of types in organic compounds and then 
by promoting the transition to the structural or constitutional view, which at present embraces, with unparalleled perfection, the whole territory of organic compounds.

But the suggestion of this doctrine, which finds, its crowning success in the recognition of the inner aggregation of the atoms, is associated for all time with the name of a man who, although a master of rare art in experimenting, knew how to surpass what he had achieved at the laboratory table by the convincing power of his speculative work. We cannot here dispute the part which other eminent chemists have taken in the development of the doctrine of structure-there are, Butlerow, C ooper, Erlenmeyer, Frankland, Kolbe, Odling, Williamsonbut the glorious guide in this great and victorious movement forward, he, to whose eyes was disclosed not only the tetravalence of carbon, but also the solution of the problem of the constitution of organic compounds, in the recognition of the property of carbon atoms to be linked to each other by their valencies; he is the philosopher of organic chemistry-A u gu st K e ku lé. The name of this discoverer, who also started upon his high and soaring flight from Heidelberg, is justly mentioned alone when we want to recall in a word the putting forth and the development of the leading chemical theories.

The researches in this direction are so numerous and so toilsome, and yet the result is so surprisingly simple! The carbon atom is endowed with four, the oxygen atom with two, the hydrogen atom with one point of attack for the chemical affinity. The cause of the aggregation of the atoms within the molecule lies in the mutual saturation of these units of affinity or valencies. It is the number of valencies which decides the possibility of the existence of a compound. Amongst the legion of imaginable combinations of these three elements only those are capable of existence in which every valency is saturated by that of another atom. Through this knowledge a new method of inquiry was opened, in particular for organic chemistry, the immense territory of which for many years seemed totally to absorb the working power of chemists. But then dawned the first signs of a further development, Hardly a decade had elapsed since the general admission 
of the doctrine of valency, when a fundamental deepening of the same was announced, which our science owes to two savants, working independently of each other-to Le B e l and va n't H off. These chemists, considering those substances which turn the plane of polarization of light, arrived at views which soon led to a result, until then thought to be out of reach, a conception of the aggregation of the atoms within the molecules in space. Thus a field of study was created which van't $\mathrm{H}$ of f called "la chimie dans l'espace" and which we now call Stereo-chemistry.

It was recognized that the carbon atom stretched out its four valencies in definite directions, and this in a symmetrical manner. The combination of a carbon atom with four other atoms, for example methane, $\mathrm{CH}_{4}$, is representable by the picture of a tetra. hedron in the stereometric centre of which the carbon atom is situated, while the hydrogen atoms occupy its four corners.

Numerous cases of isomerism until then not understood, could be explained in this manner and were regarded as stereochemical ones. The cause of optical activity was found to consist in the presence of an asymmetric curbon atom, that is, one which is combined with four different groups.

Also the stereometric forms of a few simple molecules were considered; it was recognized, e. g. that a compound of three carbon atoms linked together by one bond respectively, could not contain those atoms in a straight line, but that they must lie in the angles of a triangle the sides of which form an angle equal to that in which the directions of valency of the carbon atom intersect each other.

By the application of these considerations to more complicated molecules, which contain a chain of atoms closed within itself, A d ol ph von B a eyer has enlarged our theory in a manner full of consequence.

Kekule in times past had recognized that carbon shows a particular disposition to form closed chains of six atoms. The discoveries of B a e y e r and his followers as well as Fittig's work on lactones, taught that such closed chains or rings formed of fewer atoms also exist. But while rings of six or five atoms easily form, it is more difficult to combine fewer atoms, four or 
three, to a closed chain. The cause of this fact $\mathrm{B}$ a e y e r recognized as lying in the stereometric conditions. The angles which the sides of a regular hexagon and pentagon form with each other very nearly coincide with those, in which the directions of the valencies of the carbon atom intersect each other, and thus, in linking five or six atoms together, the circle, so to speak, closes itself, while if more or less atoms are present this can only be arrived at by strong deviation of the directions of affinity.

But still more surprising discoveries were hidden in $\mathrm{van}$ 't $\mathrm{H}$ of $f$ 's theory. The gifted Dutch thinker had penetrated to the idea that two atoms which are linked together by a single valency rotate freely around an axis the direction of which coincides with that of the linking valency, but that this rotation is stopped as soon as double linking takes place. This latter is an immediate consequence of the tetrahedric conception. If I stretch out my forefingers and let their points touch each other, then the hands can rotate around them as an axis; but if I stretch both thumbs and both forefingers and allow their corresponding points to touch each other, then a system results in which rotation is impossible.

These two propositions of $v a n$ 't $H$ of $f$ having remained almost unnoticed for a decade, have lately come into great prominence. In a series of important researches $J$ o han $n$ es $W$ is licenus has proved, that, applying these propositions and at the same time considering the specific affinities of the groups or elements present, the stereometric aggregation of the atoms in certain molecules can be determined with probability. In an ingenious manner he has utilized the addition phenomena shown by carbon atoms trebly linked together for an interpretation of a stereometric aggregation of the atoms in the compounds formed.

$W$ is licen u s, applying van't $H$ of $f$ 's ideas with courage and strictness, has advanced organic chemistry in an important manner and has opened a field for experimental research, which heretofore had been avoided with a precaution suggestive of timidity.

New discoveries came irom other sides. An intimate research into the oxims of benzil lead to the surprising result, that the validity of the second proposition of $\mathrm{van}^{\prime} \mathrm{t} H$ of $\mathrm{f}$ is not with- 
out exception. Cases were noticed, in which the free rotation of carbon atoms united by a simple bond, which ra n't $\mathrm{H}$ of $\mathrm{f}$ disclosed, diul not obtain. Further inquiry into this subject led to a renewal of the question, "What does chemicu? ralency really mean?" A question to which the mind incessantly demands an answer. It had long since been suggested that ralency had some relation to the electric behavior of the atoms. The chemistry of the day expresses Faraday's fundamental olectrolytic law thus: an electric current which flows through sercral fused electrolytes, severs in each of them the same number of ralencies-not of atoms.

It was found by ron $\mathrm{Helm}$ holt $\mathrm{z}$ that those quantities of electricity which, during the electrolytic process, move with the ions, are distributed among the ralencies. Ric $\mathrm{ke}$, in virtue of his pyroclectric researches, was led to the view that the atoms are surrounded by certain systems of positive and negative electric poles:

Uniting these results with those of purely chemical experimentation, we arrive at the idea that the ralencies do not appear as points of attack proper, but as haring linear dimensions. The carbon atom represents itself as a sphere, surrounded by au envelope of ether which contains the valencies. The latter seem to be determined by the presence of two opposite electric poles which rest at the ends of a rery short straight line. Such a system is called a dipole. The attachment of two valencies to each other consists in the attraction of their opposed poles. It is erident that in a radial position of the dipoles, they form an axis aromd which the atoms are able to rotate. but that this rotation is upset in case of a tangential position. In what his been said so fin and through further considerations in regard to the electrical charge of the atoms and of the dipoles, a reason is found for the repulsion of the four valencies and consequently for the tetraedric grouping of the same.

The fact that the valencies can deriate from this position now becomes intelligible; we perceive why the valencies of one atom cannot unite with one another, while those of different atoms can combine: it is clear that there can exist two kinds of simple link- 
ing, one of which admits of rotation, while the other does not; finally that in cases of manifold linking the free rotation must be annulled. Hence this hypothesis opens to us at understanding of the most important properties of chemical valency.

So much may be said of the problems relating to the theory of ralency.

But the doctrine of substitution has likewise experienced a peculiar enlargement. $\mathrm{D}$ u $\mathrm{m}$ a s first showed that the properties of organic compounds are generally little changed when the hydrogen of the same is replaced by univalent elements or groups. Now it has been learned from later experiments that even much more radical changes in the composition do not materially influence the properties of the substance. If, for example, we replace in the hydrocarbon benzol two carbon and two hydrogen atoms by one atom of sulphur, the resulting product, thiophen, resembles benzol, chemically and physically, so closely as to be mistaken for it. We learn from this that the sulphur atom is able to take upon itself the functions of four atoms of entirely different nature. Similar facts have been found in regard to oxygen and to the imido group, which is equivalent to it.

Turning away from these researches to cast a glance upon general chemical studies which lie some years behind us, we must above all consider one of the most far reaching discoveries of our epoch, the revelation of the natural system of the chemical elements. We owe this to the far seeing Demetrius $\mathrm{Mendel-}$ e jeff. By the side of the titanic figure of the Russian scholar we see the Englishman, $\mathrm{N}$ e w l a n d s, and our own countryman, Lothar Meyer, successfully co-operating in the foundation and the structure of this work. What these men created has since become generally known: they showed that the properties of the elements are functions of their atomic weights. M e n d ele jeff taught us to predict the existence and the properties of chemical elements as yet unknown, with a certainty that reminds us of Le Verrier's prediction of the discovery of the planet Neptune. We can say with accuracy that even to-day numerous elements, the qualities of which, as well as the place which they will occupy in the system, can be minutely foretold, wait merely to be discovered. 
The natural system has imposed upon us a problem of the greatest significance in the new determination of the atomic weights, the numerical values of which are now of increased interest. But numerous other problems are presented by the new system of the elements. Above all we are at a loss to discern the cause of the inner nexus of the elements as the system offers it. Also by diligent work the less studied elements must be properly brought within the system. Fortunate circumstances may allow us to discover the numerous elements indicated by the periodic law. Here let us note a peculiar coincidence. We know to-day about seventy elements, but Me ndelejeff's table indicates so far two small periods of seven elements each and five large ones of seventeen elements respectively. To these must be added hydrogen forming a "group" in itself.

By addition of these figures, $2 \times \hat{\imath}+5 \times 1 \hat{\imath}+1$, we obtain exactly the number 100 .

It is true that no one can say whether the missing elements will really be discovered or if further new periods might not be indicated by which this number 100 would be exceeded. But, as far as positive data are at hand, they indicate exactly the number mentioned and nothing points beyond it. An odd coincidence which seems to ally the number of the existing elements with the number of our fingers.

The discovery of the system of the elements leats us back to the question whether the chemical elements are separate worlds in themselves or whether they represent different forms or conditions under which one ultimate substance exists; a question that has occupied the philosophical mind since very early times. The same question was raised anew by the discovery of spectral analysis. Whosoever regards the numerous lines of the spectrum of a metal will hardly be convinced that the metal from which they emanate should be an eternally indecomposable element. In a similar mannel the compound nature of the elements is indicated by comparison of the regularities in numbers of the atomic weights with the homologous series of organic chemistry.

In the pursuit of this question, which, since Prout's hypothesis and the surprises offered by $\mathrm{S} t$ a s's determinations of atomic 
weights, has not been allowed to rest, positive results are not to be found. The decomposition of substances called elements into simpler ones has not been accomplished.

Nevertheless something has been achieved, since an increased interest has been drawn towards pyro-chemical research.

To-day, new methods of experiment permit of a comparatively easy determination of the vapor density, and consequently of the molecular state of the substances at the highest temperatures.

Numerous inorganic compounds, above all the very elements, have been studied in regard to their vapor density at a white heat.

While many of them, as oxygen, nitrogen, sulphur and mercury remain unchanged under such conditions, the molecules of chlorine, bromine and iodine respectively, were split into two atoms, in conformity with A vogadro's surmise of the compound na. ture of elementary molecules.

In the same manner, the vapor density and the molecular condition of the less volatile substances, zinc, thallium, antimony and bismuth, was successfully determined at a white heat.

Careful research resulted in the exposure of the old fallacy of the existence of a sulphur molecule containing six atoms.

But how many of the problems which crowd around us at this point are for the time being entirely beyond the reach of the experimenter !

To-day, pyrochemical work is limited to a temperature of $1700^{\circ}$ $\mathrm{C}$, because vessels of porcelain and platinum, to the use of which we are limited, fuse above that temperature. The possibility of performing quantitative experiments at these temperatures seemed to us some years ago to be an unexpected progress, but to-day we complain that the trivial cause of a want of proper vessels forbids us to increase the temperature up to $2000^{\circ}$ or $3000^{\circ} \mathrm{C}$. There is no doubt that we should arrive at new unthought of facts, that the splitting of still other elementary molecules would be possible, that a new chemistry would be revealed to us if, being provided with vessels of infusible material, we could work at temperatures at which water could not exist and at which detonating gas would be a non-inflammable mixture !

Let us now enter other fields of physical chemistry. Golden 
fruit, daily increasing, has been harvested upon this field during these latter days. Again we see ran't H off take the lead. His keen eye has enabled us to penetrate the nature of solution, which forms the beginning of a new epoch in molecular physics. The quintessence of his discoveries may be thus expressed:

"Solutions of different substances in the same liquid, which con. " tain in the same volume an equal number of molecules of the dis"solved substance, show the same osmotic pressure, the same vapor "pressure, and the same freezing point."

This surprising generalization offers the possibility of determining the true molecular weight of substances by experimenting upon them in solution, while heretotore this has only been possible by transforming them into the gaseous state, hence only for volatile substances, since ditute solutions behave in regard to the molecular state of the dissolved substince like gases.

In this manner new methods are given for the determination of molecular weights, which we are now able to determine by means of measurements relating to the freezing point, the vapor pressure or the nsmotic pressure of a solution of the substance to be tested.

These results are of the highest possible practical importance for chemistry, since they widen in an unexpected manner the possibility of the determination of molecular weights, and in a still higher degree we are surprised by the elucidation which they offer in regard to the nuture of solution. C 1 a u si us had already admitted within narrower limits, that in solutions of electrolytes, some of the dissolved molecules were decomposed into their ions, but now this has been proved in a larger measure, particularly by Arrhenius. What a change our conceptions will have to undergo if we have to accustom ourselves to regard a dilute solution of sodium chloride as one containing, not undecomposed molecules of this salt, but separated atoms of sodium and chlorine:

We owe these revolutionizing innorations to the investigations of $\mathrm{van}$ 't $\mathrm{H}$ off, Arrhenius. Ostwald, Planck and de Vrie but, in regard to experimental research, especially to the splendid work of $\mathrm{R}$ a o ul $\mathrm{t}$, which during recent years has effected this mighty theoretical progress. 
Thus we see Physical Chemistry moving on in weighty development. Special laboratories are opened for her and a special journal also has been started which is open alike to the records of experiment and to theoretical discussion. Through the foundation of this organ physical chemistry has been furthered in a most active manner. All the questions of the time and all those in dispute belonging to this department of science receive in this paper a thorough discussion. Dynamical-chemical questions are successfully studied, a significant impetus is given to the study of structure and affinity, (widened as our knowledge of the nature of solutions has made necessary) by means of the study of the relations between chemical nature and electric conduction.

The inquiry into the intimate relations that exist between physical and chemical properties, which was inaugurated half a century ago by $\mathrm{H}$ e r m an $\mathrm{n} \mathrm{Kop} \mathrm{p}$, is now being deepened and widened.

It is true that the great hopes which sprang from the study of thermo-chemical questions have so far been only partly fulfilled, but consecutive measurements offer more clearness also in this case.

There is no field of our science in which we may expect greater revolutions in the time near at hand than in that of physical chemistry! 'The value of these for general chemistry will be greater in proportion as the representatives of the same will recognize their task in this: above all to remain upon the chemical standpoint and to improve chemistry by the application of physical modes of thought and experiment. Those, who tried to further the progress of chemistry by the use of plysical methods but with insufficient consideration for chemical relations have been led into serious errors. The respect due to work of the highest merit, continued for years, has thus been lessened. Apparently, this has even been overdone, and it is much to be deplored if the interest of chemists for physical chemistry should be diminished because some of its representatives are inclined to overrate the value of their results. He who swims in the midst of high waves is unable at times to see over the crests.

Innumerable also, are the problems which meet us in the domain of organic chemistry.

After the astonishing harvest of synthetical results which has 
been reaped here, hardly any problem of synthesis seems unapproachable. Since the artificial preparation of alizarin by Graebe and Liebermann, of indigo by von Baeyer, of conine by Ladenburg, of uric acid by Horbaczew s $\mathrm{k}$ and jarticularly by Beh rend, since E $\mathrm{mil} F$ is che r and $\mathrm{K} i \mathrm{l}$ ia $\mathrm{n}$ i hare elucidated the chemistry of the sugar group and $I F$ a $1 \mathrm{l}$ a $\mathrm{c}$ h that of the terpenes, we may well look hopefully for a clearer knowledge of the bodies comprised under the name albumin, and to its synthesis.

$B$ ut, eren such success tends only to render us more modest, since they show us at the same time how narrow are the limits within which chemical synthesis moves. Assuming even that the preparation of albumin had been achieved-how jufinitely far we should still be from a conception of the nature of organized bodies! Perhays science is separated by an impassable chasm from the artificial preparation of a simple cell. Such an achievement lies at least beyond the sphere of chemistry.

But shall we really never succed in sounding the process of assimiletion, which in spite of its simplicity presents itself to us so enigmatically? Will it be found impossible to prepare artificially in our laboratories from carbon dioxide and water, sugar and starch, a process which natnre performs unceasingly in the green parts of plants?

The chemist however, should not step prematurely upon the field of biology, while so many great problems remain untouched in his own peculiar sphere of investigation.

The methot of research in organic chemistry, in spite of the brilliant successes already recorded, forces us even to-day to confess that snly a very minute proportion of know substances is within its reach. In order to isolate an organic substance we are generally confined to the purely aocidental properties of crystalliaction or rolatization. Have not those thousands of amorphous substances, which cannot be characterized by any chemical property, and which the chemist is forced to lay aside because he is unable either to purify them or to transiorm them in to volatile or crystallizable bodies; have they not the same claim upon our interest as their more beautiful and more manageable comrades? 
The most significant progress of organic chemistry does not consist in single discoveries, nor in further expansion of synthetical success. What we want are : New methods for recognizing the individuality of substances. The black substances of earthy nature, the innumerable formless and resinous products in the bodies of plants and animals, the coloring matter which gives beauty to flowers, all of these to-day mock our efforts to know them; they will form a new and inexhaustible field for the prosecution of chemical research, when methods shall have been found with which to begin this research.

And as in organic chemistry, so in mineral chemistry every step leads to questions, which we have as yet no means of answering. The synthesis of minerals and of rocks has made important progress, it is true, and this as well as the application of the doctrine of structure to the study of mineral species gradually leads to the understanding of their constitution. But we are, as yet, unable to use, in the study of minerals, the method of analytical decomposition which has been so successfully used to study the constitution of organic substances, and above all we lack the least knowledge in regard to the true molecular weight of minerals.

Quite recently we have been presented with no less than three new and fruitful methods for the determination of the molecular weight, but not one of them gives us an indication of the true molecular weight of the most simple oxides, such as silicic anhydride or calcium oxide.

We know to-day very well that silicic anhydride cannot have the formula $\mathrm{SiO}_{2}$, that this must be multiplied by a very large factor ; but of the numerical value of this latter we have no indica:ion. And thus also in mineral chemistry we must aim not exclusively at finding new facts but new methods of research in the first place, if a period of now discoveries is to be attained in this branch of our science.

But how can we conclude this brief review without mentioning also the applications of chemistry to the industrial arts, the progress of which have mainly contributed to spread the splendor of our science most widely? The infinite variety of the tar colors, surpassing the colors of flowers in number and brightness, is daily 
increased by new discoveries. The industry of these forms the most brilliant triumph of purely scientific laboratory work applied to manufactures. This industry in the simplest manner and on the largest scale performs the synthesis of compounds the complex nature of which is indicated by the names they bear. The unseientific man is frightened when a beautiful and brilliant dye is referred to as Hexamethylmethoxytriamidotriphenylcarbinol; for the initiated there lies in this unpleasant name a full account. of the synthesis and the constitution of the dye.

Industry has learned to derive not only colors but healing medicines also from coal tar. Antipyrin, discovered by $\mathrm{K} n$ or $r$, upon the basis of $\mathrm{Emil} \mathrm{Fischer}$ 's fundamental research upon the hydrazines, brings to thousands suffering from fever, relief at least, if not cure. Let us hope that the time is not far distant when real fever curatives, which like the natural alkaloids of the cinchona bark, not only temporarily suppress the disease but really cure it, may be prepared by synthesis. Until then be patient and do not chide chemistry if, for the time being, she offers only silver instead of gold.

Events in this field of the great chemical industries are significant. Weare the witnesses of a great combat taking place between the older process of Leblan $\mathrm{c}$ for the preparation of soda and the new one of Solva y called the Ammonia-Soda process. The intelligence and inventive genius of manufacturers have added, under the pressure of this competition, a large number of improvements to the manufacture of sulphuric acid and of soda and new and valuable methods for the preparation of chlorine. Here, more than in any other branch of chemical industry the struggle for existence is fierce.

The manufacture of iron, that most important chemical industry, is transformed by innovations. The imposing changes wrought by the older process of $B$ essemer, by the new one of Thomas, are they not based purely upon chemical reactions? The grandest application of a complicated chemical reaction to a great manufacture is, perhaps, the dephosphorizing of pig iron by lining the Bessemer converter with basic material, an invention which we owe to $T$ h o m a s and $G i l c h r i s t$. From 
this again, agriculture derives an advantage in the use of the Thomas slag containing the phosphorus which heretofore rendered iron ore less valuable. This, then, is truly a transformation of stone into bread, similar to the older manufacture of soluble fertilizers from mineral phosphates. Nevertheless, the era of bliss which was prophesied three years ago at the Berlin meeting of naturalists by our illustrious colleague, Ferd in a n d Cohn, has not yet dawned. He held that all struggles for existence amongst men, arising from want of food, the bread question, will be done away with when chemistry shall have learned to prepare starch from carbon dioxide and water. But since time immemorial the farmer is occupied in this very chemical industry, and it would hardly be great progress if the farm were merely replaced by a chemical factory. But we may reasonably hope that chemistry will teach us to make the fibre of wood a source of human food.

Indeed, if we consider how small is the quantity of starch which the grain furnishes us, and further that the wood fibre has exactly the same chemical composition as starch, we see the possibility of increasing the production of food infinitely by solving this problem: to transform celluluse into starch.

If this problem were solved we should find an inexhaustible source of human food in the wood of our forests, in grass and even in straw and chaff. The beantiful researches of $\mathrm{Hell}$ riege $\mathrm{l}$ have recently disclosed the fact, which in former times was disputed, that certain plants transform atmospheric nitrogen into albumin and that this process can be improved by suitable treatment.

The increase of albumin in plants, according to a plan, together with the production of starch out of cellulose-this would in reality signify the abolition of the bread question.

May it some day be granted to chemistry through such a discovery to inaugurate a golden age for humanity.

I have tried to give a review of the most important problems which are set before chemical science. I have mentioned a goodly number, but the short time of one hour permits me to touch but slightly upon the greater ones. There are so many problems before us, which await an immediate solution as to justify what I said in the beginning; that to-day the chemist has no time to 
complain because the epoch of a mathematical treatment of his science has not yet arrived.

Nerertheless, the brilliant successes which have been gained, the wonderful results which are immediately within our reach, have not the power to turn our eyes from this final problem.

The Newton prophesied to chemistry by Emil du Bois Rey mond, may he appear at a later period; until he comes, may many a generation honorably plow on in the sweat of its brow: We must remember that nature is not understood by us until we are able to reduce its phenomena to simple movements, mathematically traceable.

The time will come, even for chemistry, when this highest kind of treatment will prevail. The epoch in which the foremost impulse of its research was a serenely creative phantasy will then hare passed; the joys, but also the pangs and struggles, peculiar to youth, will have been overcome.

Reunited to Physics, her sister science, from whom her ways at present are separated, Chemistry will run her course with firm and unfaltering steps. 